\title{
Coulisses
}

Revue de théâtre

19 | Hiver 1999

Varia

\section{Résultats de l'enquête sur Farces}

(34 fiches recueillies au sortir de la représentation unique du 9 juin 1998)

\section{(2) OpenEdition}

\section{Journals}

Édition électronique

URL : https://journals.openedition.org/coulisses/5567

DOI : 10.4000/coulisses.5567

ISSN : 2546-9460

\section{Éditeur}

Presses universitaires de Franche-Comté

Édition imprimée

Date de publication : 1 janvier 1999

Pagination : 40

ISBN : 2-913322-09-3

ISSN : 1150-594X

\section{Référence électronique}

"Résultats de l'enquête sur Farces », Coulisses [En ligne], 19 | Hiver 1999, mis en ligne le 18 octobre 2019, consulté le 12 janvier 2022. URL : http://journals.openedition.org/coulisses/5567 ; DOI : https:// doi.org/10.4000/coulisses.5567

Ce document a été généré automatiquement le 12 janvier 2022.

Coulisses 


\section{Résultats de l'enquête sur Farces}

(34 fiches recueillies au sortir de la représentation unique du 9 juin 1998)

\begin{tabular}{|c|c|}
\hline \multicolumn{2}{|c|}{ Avez-vous déjà assisté à un spectacle du TUFC? } \\
\hline Non & 17 \\
\hline Naufrages & 11 \\
\hline Urbs & 5 \\
\hline Corps & 3 \\
\hline Équations & 3 \\
\hline Il était une fois & 3 \\
\hline Tous ou presque & 3 \\
\hline L'Épidémie & 2 \\
\hline \multicolumn{2}{|c|}{ Qu'est-ce qui vous a attiré à cette représentation? } \\
\hline Connaît un des acteurs & 23 \\
\hline Intérêt & 11 \\
\hline Venu(e) avec quelqu'un & 4 \\
\hline Invité(e) & 1 \\
\hline Hasard & 1 \\
\hline \multicolumn{2}{|c|}{ Que pensez-vous de ce spectacle? } \\
\hline Énergique & 26 \\
\hline
\end{tabular}




\begin{tabular}{|c|c|}
\hline Imaginatif & 24 \\
\hline Plaisant & 19 \\
\hline Drôle & 7 \\
\hline Reflète la société actuelle & 6 \\
\hline Magnifique & 3 \\
\hline Terrible & 3 \\
\hline Frappant & 3 \\
\hline Élégant & 2 \\
\hline Scatologique & 2 \\
\hline Émouvant & 1 \\
\hline Parfois lent & 1 \\
\hline Choquant & 1 \\
\hline Génial & 1 \\
\hline \multicolumn{2}{|c|}{ Que pensez-vous de l'interprétation des comédiens? } \\
\hline Très bonne & 15 \\
\hline Bonne & 14 \\
\hline Assez bonne & 4 \\
\hline Inégale & 1 \\
\hline \multicolumn{2}{|c|}{ Quelle partie du spectacle vous a le plus marqué(e)? } \\
\hline Le curé & 6 \\
\hline Le lit à mille places & 6 \\
\hline Les vents & 5 \\
\hline Le début & 4 \\
\hline Le banquet & 2 \\
\hline Les commères & 2 \\
\hline La femme adultère et le cocu & 2 \\
\hline Le prologue & 1 \\
\hline
\end{tabular}




\begin{tabular}{|c|c|}
\hline Le torche-cul & 1 \\
\hline L'entrée des spectateurs & 1 \\
\hline L'entrée des acteurs & 1 \\
\hline Le travail en groupe & 1 \\
\hline \multicolumn{2}{|c|}{ Certaines scènes ou certains propos du spectacle vous ont-ils choqué ? } \\
\hline Non & 24 \\
\hline Oui, et tant mieux! & 2 \\
\hline Oui & 1 \\
\hline Oui, les propos lors de la dispute & 1 \\
\hline \multicolumn{2}{|c|}{ Ce spectacle vous donne-t-il envie d'assister à d'autres créations du TUFC? } \\
\hline Oui & 34 \\
\hline \multicolumn{2}{|l|}{ Où avez-vous acheté votre place? } \\
\hline Au Kursaal juste avant le spectacle & 25 \\
\hline Invité(e) & 3 \\
\hline Auprès des étudiants & 2 \\
\hline Au bureau du TUFC & 1 \\
\hline Entrée gratuite à la fin & 1 \\
\hline \multicolumn{2}{|l|}{ Quelle profession exercez-vous? } \\
\hline Élève/étudiant & 12 \\
\hline Commerçant/artisan & 5 \\
\hline Enseignant & 5 \\
\hline Employé & 4 \\
\hline Sans profession & 4 \\
\hline Artiste & 1 \\
\hline Cadre & 1 \\
\hline Ouvrier & 1 \\
\hline
\end{tabular}




\begin{tabular}{|l|l|}
\hline Moins de 20 ans & 1 \\
\hline Entre 20 et 30 ans & 20 \\
\hline Entre 30 et 40 ans & 3 \\
\hline Entre 40 et 50 ans & 7 \\
\hline Plus de 50 ans & 2 \\
\hline Quel est votre sexe ? & \multicolumn{2}{|l|}{} \\
\hline Féminin & 26 \\
\hline Masculin & 8 \\
\hline
\end{tabular}

